\title{
Pelvic floor dysfunction 6 years post-anal sphincter tear at the time of vaginal delivery
}

\author{
David Baud • Sylvain Meyer • Yvan Vial • \\ Patrick Hohlfeld $\cdot$ Chahin Achtari
}

Received: 16 January 2011 / Accepted: 4 April 2011 /Published online: 22 April 2011

(C) The International Urogynecological Association 2011

\begin{abstract}
Introduction and hypothesis This study aims to estimate fecal, urinary incontinence, and sexual function 6 years after an obstetrical anal sphincter tear.

Methods Among 13,213 women who had a vaginal delivery of a cephalic singleton at term, 196 women sustained an anal sphincter tear. They were matched to 588 controls. Validated questionnaires grading fecal and urinary incontinence, and sexual dysfunction were completed by the participants.

Results Severe fecal incontinence was more frequently reported by women who had sustained an anal sphincter tear compared to the controls. Women with an anal sphincter tear had no increased risk of urinary incontinence, but reported significantly more pain, difficulty with vaginal lubrication, and difficulty achieving orgasm compared to the controls. A fetal occiput posterior position during childbirth was an independent risk factor for both severe urinary incontinence and severe sexual dysfunction.

Conclusions Fecal incontinence is strongly associated with an anal sphincter tear. A fetal occiput posterior position represents a risk factor for urinary incontinence and sexual dysfunction.
\end{abstract}

Keywords Anal sphincter laceration - Incontinence $\cdot$ Fetal occiput posterior position - Sexual dysfunction · Third- and fourth-degree tear

D. Baud $\cdot$ S. Meyer $\cdot$ Y. Vial $\cdot$ P. Hohlfeld $\cdot$ C. Achtari $(\bowtie)$

Department of Obstetrics and Gynecology,

University Hospital of Lausanne, Maternity-CHUV,

1011 Lausanne, Switzerland

e-mail: chahin.achtari@chuv.ch

\section{Introduction}

Vaginal delivery may be associated with serious anatomic and/or functional complications. Anal sphincter laceration during vaginal delivery is associated with instrumented deliveries, a large infant, and a fetal occiput posterior position [1-3]. Tears in the connective and muscular tissue as well as compression of the vascular supply and nerve bundles represent direct and indirect trauma responsible for defects in pelvic organ support and functional alterations of surrounding organs. A thirddegree tear increases the risk of fecal incontinence [4-6], although long-term results are conflicting [7, 8]. Nygard et al. found a large number of fecal incontinence in middleaged women, without statistical differences between the episiotomy, anal sphincter tear, or Caesarean groups [8]. Deterioration of anal continence over time and with subsequent deliveries has been described $[6,7]$, but other authors failed to confirm such results after obstetrical anal sphincter tear [9].

Moreover, little is known about the impact of such traumatic delivery on other pelvic organ function. Faltin et al. [10] reported an 18-year follow-up in 259 patients who had sustained a third-degree anal sphincter tear compared to 281 controls. The results of this study suggested that women with anal sphincter disruption had a slightly increased risk of fecal incontinence with no impact on urinary or sexual symptoms and mental or physical health [11]. In contrast, other authors reported a higher incidence of urinary symptoms $[12,13]$ and sexual dysfunction $[5,7$, $14,15]$ after anal sphincter tear.

The aim of our case-control study was to report longterm anorectal, urinary, and sexual function symptoms. Validated questionnaires addressing fecal, urinary, and sexual functions were mailed to women with and without 
previous third-degree tears. Risk factors for severe functional impairment were also identified.

\section{Materials and methods}

The case-control study was designed using our obstetrical database of prospectively collected data at the Maternity Hospital of the Centre Hospitalier Universitaire Vaudois in Lausanne, Switzerland. Data included demographic, labor, and delivery information, as well as maternal and neonatal outcomes (Tables 1 and 2). All data were collected at the time of delivery by the obstetrician. General patient data (date of birth, ethnicity, marital status, and insurance) collected at the patient admission in the hospital billing system allowed to cross-check these data, with confirmation of congruent data in $99.8 \%, 99.4 \%, 98.4 \%$, and $98.2 \%$ of cases, respectively. Specific items, such as "mode of delivery" and "mode of extraction", respectively, in the maternal and neonatal subsection of our obstetrical database allowed to cross-check this data with $99.3 \%$ congruency.

To estimate a sample size, we used five studies that evaluated fecal incontinence after an anal sphincter tear [5, $6,9,13,14]$. Based on these studies, the overall fecal incontinence rate was $40 \%(21-57 \%)$ and $20 \%(7-32 \%)$ for women with and without an anal sphincter tear, respectively.
On the basis of these estimates, we determined that a sample size of 63 cases and 189 controls would have an $80 \%$ power to detect a $20 \%$ difference with a significance level of 0.05 . Similar sample size was calculated based on the literature that evaluated sexual dysfunction [5, 14]. The literature was insufficient to determine the sample size necessary for urinary incontinence. Expecting a $40 \%$ response rate, a total of 158 and 473 patients with and without an anal sphincter tear would be necessary.

From 1996 to 2006, 13,213 women had vaginal deliveries of term singleton neonates in the cephalic presentation. Among them, 196 (1.5\%) sustained an anal sphincter tear. The anal sphincter tear was assessed by both the resident and a senior obstetrician, and classified according to the international classification of perineal tears: a third-degree tear $(n=184,94 \%)$ was defined as an injury involving the anal sphincter complex. A fourthdegree tear $(n=12,6 \%)$ was defined as injury to the perineum involving the anal sphincter and anal epithelium. Complete third- and fourth-degree anal sphincter tears were repaired by an overlap technique (including the internal anal sphincter if torn) by the resident on duty and a senior obstetrician. As described by Sultan et al., partial thirddegree tears were repaired using an end-to-end technique [16]. Mediolateral episiotomy was liberally used, whereas midline episiotomy is not used in our institution.
Table 1 Sociodemographic characteristics

\begin{tabular}{|c|c|c|c|}
\hline & Sphincter tear $(n=66) \%$ & Controls $(n=192) \%$ & $p$ Value \\
\hline Age (year+SD) & $36.4+5.7$ & $35.8+5.0$ & 0.8 \\
\hline \multicolumn{4}{|l|}{ Ethnicity } \\
\hline Swiss & 57.9 & 67.2 & \multirow[t]{2}{*}{0.2} \\
\hline Non-Swiss & 42.1 & 32.8 & \\
\hline \multicolumn{4}{|l|}{ Parity } \\
\hline 1 & 30.4 & 24.9 & \multirow[t]{2}{*}{0.4} \\
\hline$>2$ & 69.6 & 75.1 & \\
\hline \multicolumn{4}{|l|}{ Body mass index } \\
\hline$>25$ & 20.9 & 27.3 & 0.3 \\
\hline \multicolumn{4}{|l|}{ Smoke } \\
\hline No & 88.4 & 90.5 & \multirow[t]{2}{*}{0.6} \\
\hline Yes & 11.6 & 9.5 & \\
\hline \multicolumn{4}{|l|}{ University degree } \\
\hline No & 82.6 & 91 & \multirow[t]{2}{*}{0.1} \\
\hline Yes & 17.4 & 9 & \\
\hline \multicolumn{4}{|l|}{ Marital status } \\
\hline Unmarried & 14.5 & 14.3 & \multirow[t]{2}{*}{1} \\
\hline Married & 85.5 & 85.7 & \\
\hline \multicolumn{4}{|l|}{ Work status } \\
\hline Employed & 89.9 & 88.4 & \multirow[t]{2}{*}{0.7} \\
\hline Unemployed & 10.1 & 11.6 & \\
\hline \multicolumn{4}{|l|}{ Health insurance } \\
\hline Nonprivate & 97.1 & 96.3 & \multirow[t]{2}{*}{1} \\
\hline Private & 2.9 & 3.7 & \\
\hline
\end{tabular}


Table 2 Obstetric characteristics at the index delivery

\begin{tabular}{lccc}
\hline & Sphincter tear $(n=66) \%$ & Controls $(n=192) \%$ & $p$ Value \\
\hline Previous Caesarean section & 2.9 & 5.8 & 0.5 \\
Induction of labor & 34.8 & 37.6 & 0.7 \\
Epidural analgesia & 72.5 & 69.8 & 0.7 \\
Prolonged second stage $>2 \mathrm{~h}$ & 23.2 & 28.6 & 0.4 \\
Mediolateral episiotomy & 43.5 & 48.7 & 0.5 \\
Persistent occiput posterior position & 20.3 & 10.6 & 0.1 \\
Type of vaginal delivery & & & \\
$\quad$ Normal & 66.7 & 61.9 & 0.8 \\
$\quad$ Forceps & 31.9 & 36.5 & \\
$\quad$ Vacuum & 1.5 & 1.6 & 0.7 \\
Birth weight $>90$ th percentile & 10.1 & 11.6 & \\
\hline
\end{tabular}

The 196 cases were matched regarding age, parity, ethnicity, year of delivery, birth weight, previous Caesarean, mode of vaginal delivery (normal, forceps, vacuum extraction), and episiotomy. Three controls $(n=588)$ were chosen for each case $(n=196)$. The case and control groups both received the same questionnaires by mail. Last address mentioned when consulting the hospital was used to mail the patient. Nonresponders received a second mail 6 weeks later. A total of 189 patients (24\%) no longer had current addresses listed in our hospital. We traced these women's current home address with the telephone directory. Seventy-four (9\%) women could not be located. The study was approved by the Ethical Committee of the University and Hospital, Lausanne, Switzerland (protocol 101/08; date of approval, May 6, 2008). Responding to the questionnaires was considered informed consent to participate in the study.

Current social, demographic, and physical patients' characteristics were registered using a self-reported questionnaire. Obstetrical data about the history and mode of delivery of subsequent birth (that might have occurred in other hospitals) were collected. Obstetrical data from our computerized database allowed cross-checking of obstetrical events reported in the questionnaire. Age, year, and mode of deliveries confirmed congruent answers in $100 \%$, $100 \%$, and $98 \%$ of cases, respectively. Four validated questionnaires were also used: the modified Wexner fecal incontinence scale of Vaisey et al. [17, 18], short forms of the Urogenital Distress Inventory (UDI-6), the Incontinence Impact Questionnaire (IIQ-7) [19, 20], and the Female Sexual Function Index (FSFI) [21, 22]. Cutoffs for severe fecal or urinary incontinence and severe sexual dysfunction were selected by consensus before the statistical analysis (UDI-6) or from the literature (Wexner scale [23, 24] and FSFI [25]).

Fecal incontinence was evaluated using Wexner fecal incontinence scale of Vaisey et al. [17, 18]. The modified Wexner scale consists of eight items (Table 3), each item scores between 0 and 4 related to the frequency of occurrence ( 0 , absent; 1 , less than once a month; 2 , less than once a week; 3, less than once a day; 4, daily). A Wexner score of 0 means absence of fecal incontinence and a score of 20 means complete incontinence. Severe and very severe fecal incontinence were defined as a Wexner score $\geq 5$ and $\geq 8$, respectively $[23,24]$.

The UDI-6 and IIQ-7 are validated indices to assess urinary incontinence $[19,20]$. The UDI-6 measures the

Table 3 Wexner anal incontinence score

\begin{tabular}{|c|c|c|c|c|c|}
\hline Symptoms & Sphincter tear $(n=66) \%$ & Controls $(n=192) \%$ & $p$ Value & $\mathrm{RR}$ & $95 \% \mathrm{CI}$ \\
\hline Incontinence for gas & 52.1 & 36.7 & 0.025 & 1.88 & $1.08-3.29$ \\
\hline Incontinence for liquid stool & 21.7 & 9 & 0.01 & 2.79 & $1.31-5.97$ \\
\hline Incontinence for solid stool & 5.9 & 3.2 & 0.464 & 1.90 & $0.52-6.93$ \\
\hline Alteration of lifestyle & 15.9 & 5.4 & 0.01 & 3.36 & $1.36-8.31$ \\
\hline Alteration of sexual life & 9 & 2.2 & 0.024 & 4.45 & $1.22-16.3$ \\
\hline Need to wear a pad & 11.6 & 7.5 & 0.317 & 1.63 & $0.65-4.08$ \\
\hline Taking constipating medicine & 0 & 0.54 & 1 & & \\
\hline Inability to defer defecation for $15 \mathrm{~min}$ & 15.9 & 10.1 & 0.196 & 1.69 & $0.76-3.76$ \\
\hline Mean Wexner score $(95 \% \mathrm{CI})$ & $2.3(1.4-3.2)$ & $1.2(0.9-1.5)$ & 0.004 & & \\
\hline
\end{tabular}


bothersomeness of urinary incontinence symptoms, with higher scores indicating a greater degree of bother or a worse quality of life. The IIQ-7 measures the impact of urinary incontinence on activities, roles, and emotional states, with higher scores indicating a greater impact or a worse quality of life. For both questionnaires, each item is categorized by the frequency of occurrence or discomfort (never/slightly/moderately/much). Severe urinary incontinence was defined as a UDI- 6 score $\geq 4$.

The FSFI is a validated instrument for the assessment of sexual function. This multidimensional score combines 18 questions in six subscales (desire, arousal, lubrication, orgasm, satisfaction, and pain). The score ranges from 2 to 36 , with high scores representing high sexual activity and satisfaction and low scores signifying sexual difficulties or little sexual activity. Severe sexual dysfunction was defined as FSFI scores $\leq 25$ [25].

Since we expected that most women would not report any symptoms and to avoid reporting very skewed distributions, we dichotomized ordinal outcomes of each questionnaire. The effect of the exposure, demographic data, and risk factors were compared between patients with and without anal sphincter tear by the Pearson $\chi^{2}$ test (or the Fisher's exact test when indicated) for categorical variables. For continuous variables, medians were compared by the Student's $t$ test (when normally distributed) or the Wilcoxon test (when non-normally distributed). Multivariate logistic regressions were performed to identify factors independently associated with severe fecal or urinary incontinence and severe sexual dysfunction. Statistical analyses were performed using STATA-10 (Stata Corporation, College Station, USA).

\section{Results}

From our hospital database, 784 patients were identified for this study (196 with and 588 without anal sphincter tear, ratio 1:3). Among the 710 (91\%) women who were localized, $258(36 \%)$ completed the questionnaires. Demographic and obstetrical characteristics of responders were similar to those of nonresponders or lost patients (data not shown). Specifically, 66/176 (37.5\%) and 192/534 (36\%) women with and without anal sphincter tear, respectively, returned the questionnaires $(p=0.7)$. The mean time between delivery and response to the questionnaires was $5.8(95 \%$ confidence intervals $[95 \% \mathrm{CI}] 5.1-6.4)$ and 6.1 (95\%CI 5.7-6.5) years for women with and without anal sphincter tear, respectively $(p=0.8)$.

Table 1 shows sociodemographic characteristics of women with and without anal sphincter tear at the time they answered the questionnaires. Cases and controls did not exhibit any significant differences. Table 2 shows no difference in obstetrical characteristics of women with and without anal sphincter tear at the index delivery. Further deliveries after the index delivery were reported by $58 \%$ of women with and $55 \%$ of women without anal sphincter tear $(p=0.8)$.

After anal sphincter tear, women were more likely to pass involuntary flatus and liquid stools (Table 3). Women who sustained anal sphincter tear were also more likely to pass involuntary solid stool, although the differences did not reach significance. Incontinence to gas, liquid, or solid was reported at least once in $57.4 \%$ and $39.5 \%$ of women with and without anal sphincter tear $(p=0.01$, risk ratio [RR] 2.1, 95\%CI 1.2-3.6). Similarly, alteration of lifestyle and/or sexual life caused by fecal incontinence was more likely reported after anal sphincter tear. The need to wear a sanitary pad and the inability to defer defecation for $15 \mathrm{~min}$ were also greater after anal sphincter tear but did not reach statistical significance. The need to use constipating medicine was rarely mentioned in either group. When considering all symptoms together, the mean Wexner fecal incontinence score was $2.3(95 \% \mathrm{CI} 1.4-3.2)$ and $1.2(95 \%$ CI 0.9-1.5) for women with and without anal sphincter tear $(p<0.005)$. Severe fecal incontinence (defined as a Wexner score $\geq 5$ ) was reported by $15.4 \%$ of women with and $6.6 \%$ of women without anal sphincter tear $(p=0.04$, RR 2.6, 95\%CI 1.1-6.3). When all sociodemographic and obstetric variables (Tables 1 and 2) were considered, independent factors associated with severe fecal incontinence were anal sphincter tear (RR 2.1, 95\%CI 1.1-3.9) and instrumental vaginal delivery (RR 2.3, 95\% CI 1.3-4.2). Age, parity, further deliveries, birth weight, episiotomy, and time since the index delivery were not independent factors associated with severe fecal incontinence. Very severe fecal incontinence (defined as a Wexner score $\geq 8$ ) was reported by seven $(10.6 \%)$ women with anal sphincter tear and four (2.1\%) controls $(p<0.01$, RR $5.495 \%$ CI $1.5-19.0)$.

After anal sphincter tear (Table 4), women were more likely bothered by frequent urination $(p<0.001$, RR 3.4, $95 \%$ CI 1.7-6.5). There was no significant difference in any other urinary symptoms. When considering all symptoms together, the mean UDI-6 score was higher for women with anal sphincter tear $(3.2,95 \% \mathrm{CI} 2.4-3.9)$ as compared to controls $(2.6,95 \% \mathrm{CI} 2.2-3.0)$, although this difference did not reach significance $(p=0.158)$. Similarly, the incidence of severe urinary incontinence (defined as a UDI-6 score $\geq 4$ ) was not significantly different between women in the study or control groups (37.9\% versus $31.1 \%, p=0.361)$. When all sociodemographic and obstetric variables included in Tables 1 and 2 were considered, independent factors associated with severe urinary incontinence were smoking $(p=0.034$, RR 2.49, 95\%CI 1.07-5.76) and a fetal occiput posterior position at the index delivery $(p=0.042$, RR $2.18,95 \% \mathrm{CI}$ 
Table 4 Urinary distress inventory (UDI-6)

\begin{tabular}{|c|c|c|c|c|c|}
\hline Moderate to great symptoms & Sphincter tear $(n=66) \%$ & Controls $(n=192) \%$ & $p$ Value & RR & $95 \% \mathrm{CI}$ \\
\hline Frequent urination & 33.3 & 13 & $<0.0001$ & 3.35 & $1.74-6.48$ \\
\hline Urine leakage related to urgency & 8.8 & 9.3 & 1 & 0.94 & $0.36-2.51$ \\
\hline Urine leakage related to physical activity & 14.9 & 16.1 & 0.817 & 0.91 & $0.42-1.98$ \\
\hline Small amounts of urine leakage (drops) & 10.3 & 8.1 & 0.616 & 1.31 & $0.51-3.36$ \\
\hline Difficulty emptying bladder & 5.9 & 6.5 & 1 & 0.90 & $0.28-2.89$ \\
\hline Lower abdominal or genital pain & 10.3 & 8 & 0.615 & 1.32 & $0.51-3.38$ \\
\hline Mean UDI-6 score (95\% CI) & $3.1+2.9$ & $2.6+2.8$ & 0.158 & & \\
\hline
\end{tabular}

1.03-4.62). Women who sustained an anal sphincter tear more often reported urine leakage during physical activities at home (Table 5, 5.9\% versus $1.1 \%, p=0.048$, RR $5.7,95 \% \mathrm{CI} 1.0-31.6)$. There was no difference in the other items of the IIQ-7 questionnaire nor in the IIQ-7 score $(p=0.337)$.

None of the women reported absence of sexual activity. None of the subscores for desire, excitation, lubrication, orgasm, satisfaction or pain, nor the global FSFI score showed significant difference between women with and without anal sphincter tear (Table 6). However, women who sustained anal sphincter tear reported significantly more difficulties in one question relating to lubrication (question 7) and more pain following vaginal penetration (question 18) than controls. Moreover, reaching orgasm (question 12) was significantly more difficult for women with anal sphincter tear than controls. The subscore concerning orgasm was also lower for women after anal sphincter tear with borderline significant difference $(p=0.068)$. When all sociodemographic and obstetric variables (Tables 1 and 2) were considered, independent factors associated with severe sexual dysfunction (defined as a FSFI score $\leq 25$ ) were a fetal occiput posterior position at the index delivery ( $p=0.012$, RR $2.81,95 \%$ CI 1.26-6.31) and whether the women was unemployed $(p=0.014$, RR $2.98,95 \% \mathrm{CI} 1.25-7.12)$. Having more than one child $(p<0.001$, RR $0.18,95 \%$ CI $0.07-0.45)$ was a protective factor. Age, anal sphincter tear, and episiotomy were not independent factors associated with severe sexual dysfunction.

When considering fecal, urinary, and sexual questionnaires together, 118 women presented at least one severe dysfunction (Wexner score $\geq 5$ or UDI- 6 score $\geq 4$ or FSFI score $\leq 25$, Fig. 1). Among these 118 women, 69 (58\%), 40 (34\%), and nine (8\%) reported severe dysfunction of either 1, 2, or 3 systems (Fig. 1), respectively.

\section{Discussion}

The reported incidence of anal sphincter tears identified clinically at the time of vaginal delivery ranges from $0.6 \%$ to $19 \%$ [1-3]. Anal sphincter tears can be evident, unrecognized or occult, which could explain such a high variation in reported incidences. Indeed, unrecognized or occult anal tear occurs in up to $25 \%$ of primiparous women [26]. In our cohort, $1.5 \%$ of women who delivered vaginally sustained an anal sphincter tear, which belongs to the low range of incidences described in the literature [1-3]. Misclassification of both controls (suspected intact sphincter) and cases (anal sphincter tear) might have reduced the strength of the associations observed in the present study.

The strengths of our study were the use of validated and detailed questionnaires exploring all three pelvic floor

Table 5 Incontinence impact questionnaire (IIQ-7)

\begin{tabular}{|c|c|c|c|c|c|}
\hline Urine leakage during: & Sphincter tear $(n=66) \%$ & Controls $(n=192) \%$ & $p$ Value & RR & $95 \% \mathrm{CI}$ \\
\hline Physical activities at home & 5.9 & 1.1 & 0.048 & 5.66 & $1.01-31.6$ \\
\hline Physical activities outside home & 14.7 & 12.5 & 0.676 & 1.21 & $0.54-2.68$ \\
\hline Entertainment activities (cinema...) & 4.4 & 2.2 & 0.39 & 2.09 & $0.46-9.58$ \\
\hline Travel longer than $30 \mathrm{~min}$ & 2.9 & 3.2 & 1 & 0.90 & $0.18-4.57$ \\
\hline Social activities & 2.9 & 2.2 & 0.662 & 1.36 & $0.24-7.62$ \\
\hline Feeling anxious or depressive & 16.2 & 14.7 & 0.843 & 1.12 & $0.55-2.41$ \\
\hline Feeling frustrated & 11.8 & 13.7 & 0.693 & 0.84 & $0.36-1.97$ \\
\hline Mean IIQ-7 score $(95 \% \mathrm{CI})$ & $1.0+2.8$ & $0.7+1.6$ & 0.337 & & \\
\hline
\end{tabular}


Table 6 Female Sexual Function Index (FSFI)

\begin{tabular}{|c|c|c|c|c|c|}
\hline FSFI questionnaire & $\begin{array}{l}\text { Sphincter } \\
\text { tear } \\
(n=66) \%\end{array}$ & $\begin{array}{l}\text { Controls } \\
(n=192) \\
\%\end{array}$ & $\begin{array}{l}p \\
\text { Value }\end{array}$ & $\mathrm{RR}$ & $95 \% \mathrm{CI}$ \\
\hline Sexual desire half of the time or less & 24.2 & 23.4 & 0.867 & 1.04 & $0.54-1.86$ \\
\hline Low level of sexual desire & 13.6 & 20.0 & 0.352 & 0.63 & $0.29-1.39$ \\
\hline Score "DESIRE" (1.2-6) & $3.8+1.0$ & $3.8+1.2$ & 0.746 & & \\
\hline Excitation during sexual activity half of the time or less & 12.1 & 12.8 & 1 & 0.94 & $0.40-2.22$ \\
\hline Low level of excitation during sexual activity & 13.6 & 11.1 & 0.655 & 1.27 & $0.55-2.94$ \\
\hline Low confidence about becoming sexually excited during sexual activity & 14.9 & 9.4 & 0.252 & 1.69 & $0.73-3.85$ \\
\hline Satisfied with excitation during sexual activity less than half the time & 16.4 & 10.5 & 0.272 & 1.67 & $0.75-3.70$ \\
\hline Score "EXCITATION" (0-6) & $4.2+1.3$ & $4.5+1.1$ & 0.181 & & \\
\hline Lubrication during sexual activity less than half of the time & 24.2 & 13.3 & 0.03 & 2.08 & $1.04-4.17$ \\
\hline Difficulty becoming lubricated during sexual activity & 11.9 & 8 & 0.329 & 1.56 & $0.62-3.85$ \\
\hline Maintain lubrication until completion of sexual activity less than half of the time & 10.5 & 13.4 & 0.668 & 0.75 & $0.31-1.85$ \\
\hline Difficulty maintaining lubrication until completion of sexual activity 7.5 & 7.5 & 6.3 & 0.774 & 1.20 & $0.40-3.57$ \\
\hline Score "LUBRIFICATION" (0-6) & $4.7+1.4$ & $4.8+1.4$ & 0.438 & & \\
\hline Reach orgasm less than half of the time & 22.7 & 13.3 & 0.08 & 1.92 & $0.93-3.85$ \\
\hline Reaching orgasm difficult & 31.3 & 16.7 & 0.011 & 2.27 & $1.19-4.35$ \\
\hline Moderately dissatisfied with ability to reach orgasm & 20.1 & 16 & 0.45 & 1.39 & $0.68-2.86$ \\
\hline Score "ORGASM" (0-6) & $4.2+1.6$ & $4.6+1.3$ & 0.068 & & \\
\hline $\begin{array}{l}\text { Moderately satisfied with the amount of emotional closeness during sexual } \\
\text { activity }\end{array}$ & 20.9 & 15.5 & 0.342 & 1.45 & $0.71-2.94$ \\
\hline Moderately dissatisfied about the sexual relationship & 13.4 & 10.1 & 0.493 & 1.39 & $0.59-3.23$ \\
\hline Moderately dissatisfied about overall sexual life & 16.4 & 11.7 & 0.394 & 1.49 & $0.68-3.23$ \\
\hline Score "SATISFACTION" (0-6) & $4.3+1.4$ & $4.5+1.2$ & 0.353 & & \\
\hline Pain during vaginal penetration about half the time or more & 28.4 & 25.7 & 0.746 & 1.15 & $0.61-2.13$ \\
\hline Pain following vaginal penetration more than half of the time & 10.5 & 3.3 & 0.048 & 3.33 & $1.10-11.1$ \\
\hline High level of pain during or following vaginal penetration & 9 & 4.5 & 0.216 & 2.08 & $0.70-6.67$ \\
\hline Score "PAIN" (0-6) & $4.8+1.6$ & $5.2+1.1$ & 0.107 & & \\
\hline SCORE TOTAL (2-36) & $26.1+6.8$ & $27.3+5.9$ & 0.185 & & \\
\hline
\end{tabular}

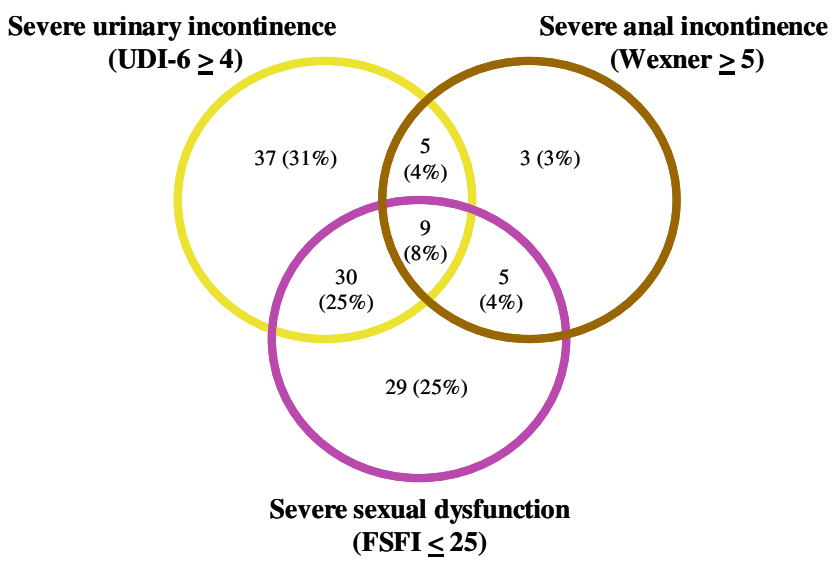

Fig. 1 Distribution of the 118 patients presenting severe anal incontinence, urinary incontinence and/or sexual dysfunction functions in study and control groups, which were similar in their sociodemographic and obstetrical characteristics. The limitation of the present study was the overall response rate of $36 \%$, which may appear low in comparison to other studies [5, 7, 9-11]. However, we did not contact women by phone before sending the questionnaires $[10,11]$ nor ask them to participate in the study in the direct postpartum period [6], or considered a group of women that had already participated in a previous study [5, 7, 9], which might all induce a selection bias. Similar response rates (32-33\%) were obtained by others who mailed a brief questionnaire about pelvic floor symptoms in an unselected group of women after vaginal birth [13]. Response rate might have been improved by being more selective and minimizing the number of questionnaire. One other limitation was the absence of a baseline symptom assessment. It was thus impossible to know whether urinary/fecal incontinence or sexual dysfunctions were present a priori or whether symptoms were attributable to the anal sphincter laceration. 
Our study of women, who had suffered from anal sphincter tears, was designed to evaluate their current symptoms compared with a matched control group. We demonstrated that women who sustained obstetric anal sphincter tears have an increased risk of reporting severe fecal incontinence 6 years after the index delivery. Similar associations were found by others although they used fecal incontinence scoring questionnaire that were not validated [5-7, 9, 13, 14]. Previous studies with long term follow-up (more than 18 years) showed poor association between anal sphincter tear and fecal incontinence [8, 10]. However, these studies reported high incidence of fecal incontinence both in cases and controls $[8,10]$. This may be explained by two factors: duration of the follow-up equalizing rather than an exacerbating fecal incontinence [8] and the use of midline episiotomies. Indeed, the difference in reporting symptoms between women who sustained an anal sphincter tear or not might decrease with age, since age itself is an independent risk factor for fecal incontinence $[6,10]$. In contrast to our study, both studies reported use of midline episiotomies $[8,10]$, which is known to be associated with higher rates of sphincter tears and fecal incontinence [3, 13]. The present study indicates that instrumental delivery and anal sphincter tear were risk factors for developing severe fecal incontinence. These findings are consistent with previously reported findings $[6,10]$. However, neither subsequent childbirth [6], nor age [6, 10] nor other variables associated with a difficult vaginal delivery were associated with severe fecal incontinence in our study.

Our data suggest that women who sustained anal sphincter tears have no increased risk of urinary incontinence. This confirms results published by others $[11,13$, 14]. Surprisingly, high prevalence of urinary incontinence symptoms was reported, with more than $16 \%$ of urine leakage related to physical activity in the control group. Women who were most bothered by their symptoms were probably more likely to return the questionnaire than women without symptoms, which might also be true for the other pelvic functions. Both maternal smoking and the fetal occiput posterior position during delivery were independent factors associated with severe urinary incontinence. No other variables associated with difficult vaginal delivery, including anal sphincter tear, predict urinary incontinence. Maternal smoking is a well-known bladder irritant [27]. Fetal occiput posterior position during childbirth might induce pudendal nerve affliction [28-30] and muscle trauma altering urethral support [31, 32] leading to an increased risk of urinary incontinence.

Concerning sexual function, women who sustained anal sphincter tear reported significantly more alteration of their sexual life in the Wexner questionnaire. However, subscores and global score of the FSFI questionnaire did not confirm this association, although some specific questions related to lubrication, orgasm, and pain showed significant differences between the two groups. Other authors found similar results concerning specific questions relating to lubrication [7, 11] and pain [5, 14]. The discrepancy between the sexual question of the modified Wexner score and the FSFI score is not clear. Wexner questions may be interpreted by the patients as assessing the effect of fecal incontinence on intercourse when fecal incontinence occurs during intercourse, whereas patients' answers for the FSFI most likely is more reflective of overall sexual function. Similar to severe urinary incontinence, fetal occiput posterior position during childbirth was strongly associated with severe sexual dysfunction. The mechanisms leading to sexual dysfunction might be scar tissue at the vaginal introitus or pudendal neuropathy. Interestingly, three women spontaneously reported loss of vaginal orgasms with persistence of clitoridian orgasms.

We have demonstrated an association between anal sphincter injury and fecal incontinence 6 years after birth. The impact of anal sphincter tear on urinary incontinence and sexual function needs further investigations. Our study highlights the role of the fetal occiput posterior position during childbirth. Persistent occiput posterior position leads to a sevenfold increase in the incidence of anal sphincter injury [1, 2, 33-35], and also significantly increases the risk of severe urinary incontinence and severe sexual dysfunction. When clinicians recognize the persistence of an occiput posterior position, it is questionable whether fetal head manual rotation should be attempted or Caesarean section proposed [35]. In this situation, women should be at least informed of the long-term consequences.

Acknowledgment We thank all midwives and doctors who computerized obstetrical data used in this study. Their involvement was essential to the whole process and they enthusiastically gave their time to allow this study. We thank Cristina Lyko, Sarah Guidon, Christian Sinobas and Andre Baud for computer assistance, Olivia and Felix Sandri for sending the questionnaire, Kelsey Mills and Paulina Cybulska for critical review of the manuscript.

Funding The study was funded by the Foundation for Research and Development in Gynecology and Obstetrics of Lausanne, Switzerland. David Baud is supported by the "Société Académique Vaudoise" through the "Paul Blanc" grant and the SICPA Foundation. The funding sources had no role in the study design, data collection, data analysis or the interpretation thereof, or writing of the report.

Conflicts of interest None.

\section{References}

1. Fitzgerald MP, Weber AM, Howden N, Cundiff GW, Brown MB (2007) Risk factors for anal sphincter tear during vaginal delivery. Obstet Gynecol 109:29-34 
2. Wheeler TL, Richter HE (2007) Delivery method, anal sphincter tears and fecal incontinence: new information on a persistent problem. Curr Opin Obstet Gynecol 19:474-479

3. Dudding TC, Vaizey CJ, Kamm MA (2008) Obstetric anal sphincter injury: incidence, risk factors, and management. Ann Surg 247:224-237

4. Vaccaro C, Clemons JL (2008) Anal sphincter defects and anal incontinence symptoms after repair of obstetric anal sphincter lacerations in primiparous women. Int Urogynecol J Pelvic Floor Dysfunct 19:1503-1508

5. Mous M, Muller SA, de Leeuw JW (2008) Long-term effects of anal sphincter rupture during vaginal delivery: faecal incontinence and sexual complaints. BJOG 115:234-238

6. Pollack J, Nordenstam J, Brismar S, Lopez A, Altman D, Zetterstrom J (2004) Anal incontinence after vaginal delivery: a five-year prospective cohort study. Obstet Gynecol 104:1397-1402

7. Fornell EU, Matthiesen L, Sjodahl R, Berg G (2005) Obstetric anal sphincter injury ten years after: subjective and objective long term effects. BJOG 112:312-316

8. Nygaard IE, Rao SS, Dawson JD (1997) Anal incontinence after anal sphincter disruption: a 30-year retrospective cohort study. Obstet Gynecol 89:896-901

9. Nordenstam J, Altman D, Brismar S, Zetterstrom J (2009) Natural progression of anal incontinence after childbirth. Int Urogynecol J Pelvic Floor Dysfunct 20:1029-1035

10. Faltin DL, Boulvain M, Floris LA, Irion O (2005) Diagnosis of anal sphincter tears to prevent fecal incontinence: a randomized controlled trial. Obstet Gynecol 106:6-13

11. Otero M, Boulvain M, Bianchi-Demicheli F, Floris LA, Sangalli MR, Weil A, Irion O, Faltin DL (2006) Women's health 18 years after rupture of the anal sphincter during childbirth: II. urinary incontinence, sexual function, and physical and mental health. Am J Obstet Gynecol 194:1260-1265

12. Scheer I, Andrews V, Thakar R, Sultan AH (2008) Urinary incontinence after obstetric anal sphincter injuries (OASIS) - is there a relationship? Int Urogynecol J Pelvic Floor Dysfunct 19:179-183

13. Fenner DE, Genberg B, Brahma P, Marek L, DeLancey JO (2003) Fecal and urinary incontinence after vaginal delivery with anal sphincter disruption in an obstetrics unit in the United States. Am J Obstet Gynecol 189:1543-1549

14. Wagenius J, Laurin J (2003) Clinical symptoms after anal sphincter rupture: a retrospective study. Acta Obstet Gynecol Scand 82:246-250

15. Brubaker L, Handa VL, Bradley CS, Connolly A, Moalli P, Brown MB, Weber A (2008) Sexual function 6 months after first delivery. Obstet Gynecol 111:1040-1044

16. Sultan AH, Monga AK, Kumar D, Stanton SL (1999) Primary repair of obstetric anal sphincter rupture using the overlap technique. Br J Obstet Gynaecol 106:318-323

17. Jorge JM, Wexner SD (1993) Etiology and management of fecal incontinence. Dis Colon Rectum 36:77-97

18. Vaizey CJ, Carapeti E, Cahill JA, Kamm MA (1999) Prospective comparison of faecal incontinence grading systems. Gut 44:77-80

19. Shumaker SA, Wyman JF, Uebersax JS, McClish D, Fantl JA (1994) Health-related quality of life measures for women with urinary incontinence: the Incontinence Impact Questionnaire and the Urogenital Distress Inventory. Continence Program in Women (CPW) Research Group. Qual Life Res 3:291-306

20. Uebersax JS, Wyman JF, Shumaker SA, McClish DK, Fantl JA (1995) Short forms to assess life quality and symptom distress for urinary incontinence in women: the Incontinence Impact Questionnaire and the Urogenital Distress Inventory. Continence Program for Women Research Group. Neurourol Urodyn 14:131-139

21. Meston CM (2003) Validation of the Female Sexual Function Index (FSFI) in women with female orgasmic disorder and in women with hypoactive sexual desire disorder. J Sex Marital Ther 29:39-46

22. Rosen R, Brown C, Heiman J, Leiblum S, Meston C, Shabsigh R, Ferguson D, D'Agostino R Jr (2000) The Female Sexual Function Index (FSFI): a multidimensional self-report instrument for the assessment of female sexual function. J Sex Marital Ther 26:191208

23. Mahony R, Behan M, Daly L, Kirwan C, O'Herlihy C, O'Connell PR (2007) Internal anal sphincter defect influences continence outcome following obstetric anal sphincter injury. Am J Obstet Gynecol 196:217.e1-5

24. Faltin DL, Otero M, Petignat P, Sangalli MR, Floris LA, Boulvain $\mathrm{M}$, Irion O (2006) Women's health 18 years after rupture of the anal sphincter during childbirth: I. fecal incontinence. Am J Obstet Gynecol 194:1255-1259

25. Wiegel M, Meston C, Rosen R (2005) The female sexual function index (FSFI): cross-validation and development of clinical cutoff scores. J Sex Marital Ther 31:1-20

26. Andrews V, Sultan AH, Thakar R, Jones PW (2006) Occult anal sphincter injuries - myth or reality? BJOG 113:195-200

27. Holroyd-Leduc JM, Straus SE (2004) Management of urinary incontinence in women: scientific review. JAMA 291:986-995

28. Sultan AH, Kamm MA, Hudson CN (1994) Pudendal nerve damage during labour: prospective study before and after childbirth. Br J Obstet Gynaecol 101:22-28

29. Allen RE, Hosker GL, Smith AR, Warrell DW (1990) Pelvic floor damage and childbirth: a neurophysiological study. Br J Obstet Gynaecol 97:770-779

30. Snooks SJ, Setchell M, Swash M, Henry MM (1984) Injury to innervation of pelvic floor sphincter musculature in childbirth. Lancet 2:546-550

31. Dietz HP, Lanzarone V (2005) Levator trauma after vaginal delivery. Obstet Gynecol 106:707-712

32. Kearney R, Miller JM, Ashton-Miller JA, DeLancey JO (2006) Obstetric factors associated with levator ani muscle injury after vaginal birth. Obstet Gynecol 107:144-149

33. Fitzpatrick M, McQuillan K, O'Herlihy C (2001) Influence of persistent occiput posterior position on delivery outcome. Obstet Gynecol 98:1027-1031

34. Ponkey SE, Cohen AP, Heffner LJ, Lieberman E (2003) Persistent fetal occiput posterior position: obstetric outcomes. Obstet Gynecol 101:915-920

35. Simkin P (2010) The fetal occiput posterior position: state of the science and a new perspective. Birth 37:61-71 